\title{
Application of Network Technology in Distance Education of Physical Education Curriculum-Take the Football Course as an Example*
}

\author{
Chen $\mathrm{Qu}^{1}$ \\ Northeast Normal University
}

\begin{abstract}
Modern distance physical education is a complex system engineering, so we must set up an open sports concept. In this paper, we take the football course as an example, a networked learning platform for school physical education based on network technology has been designed. This kind of learning platform makes full use of the advantages of network education and uses the openness and sharing of network technology to build a remote network learning platform which is beneficial to students' independent learning, cooperative learning and exploratory learning. This platform can provide students with abundant sports learning resources, increase the time and space for students to learn independently, and promote the transformation of sports learning methods. The development of distance education in China's physical education curriculum is still in its infancy. In this context, the development of physical education to modern distance education is particularly necessary.
\end{abstract}

\section{Keywords}

Network Technology • Physical Education Curriculum • Football Course • Distance Education

\footnotetext{
* This work is supported by the "Thirteen-Five" project of social science research: college students football league (CUFL) commercialization research (Project number: JLKH20180048SK).

${ }^{1}$ Correspondence to: Chen Qu (PhD), Northeast Normal University, Changchun 130024, China. Email: quc706@nenu.edu.cn 
In recent years, China's social economy has taken rapid development and achieved remarkable results (Beltran-Carrillo, Devis-Devis, Peiro-Velert \& Brown, 2012). The overall quality of the whole people has been continuously improved. People's intentions for lifelong learning and the pursuit of health have increased day by day. At the same time, China's national fitness program and Sunshine Sports have been further implemented and popularized. Sports has become the wing of people's consumer goods, and the demand for sports has surged, which make the scale and speed of the sports education market grow amazing (Galán et al., 2014). Faced with this trend, traditional physical education can no longer meet the needs of development. Therefore, a new physical education model that injects new vitality into the implementation of lifelong sports has raised the modern distance education of sports.

Modern distance education is a face-to-face education from which is different from regular schools. Instead, it uses advanced information technology and network technology to create an open, flexible and equal centreless network that facilitates communication, interaction and sharing of information across time and space (Gao, Podlog \& Huang, 2013). It is a new type of education and teaching model to achieve the environment. Sports modern distance education refers to a new method, concept and organization form of physical education methods that is realized by using modern information technology to create an open, flexible and equal noncentral network environment that is easy to communicate and interact with each other and share information (Cardinal, Yan \& Cardinal, 2013).

With the rapid development of economic globalization and the rapid advancement of science and technology, the development of computer information technology, communication technology, internet technology, and visual multimedia technology can be described as ever-changing. These modern technologies have been deeply integrated into people's daily life. The emergence and development of new science and technology are gradually bringing influence and changing people's traditional way of life while bringing convenience to people. With the development of network technology, human beings have entered a new era of knowledge and network. The reform and development of education, the level of innovation in science and technology knowledge determines the comprehensive national strength of a country and its ability to compete in the entire world. How to use modern science and technology to improve and perfect contemporary physical education is a constant research topic.

\section{Research Status}

\section{The popularization of network technology}

Through the investigation and analysis of the latest information published by relevant authoritative websites in the Internet, it is found that the current level of construction and development of China's network teaching platform has become unevenly distributed. In the economically developed eastern and central regions and some colleges and universities, the construction and development of multimedia network teaching platforms have begun to take shape, while the western regions of some underdeveloped economies and the multimedia network teaching platforms of most universities are still in the initial exploration and development. According to the 
latest survey of China Internet Network Information Centre, the total number of Internet users in China reached 7.5116 billion by the end of June 2018. Compared with the previous year, the number of new Internet users in the country was 41.58 million, and the penetration rate of the Internet was $54.3 \%$. At the end of 2016, it increased by $2.6 \%$. Figure 1 shows the scale and penetration rate of Chinese netizen from 2015 to 2018.

It can be seen from Figure 1 that Chinese netizen has grown from 64875 million in 2015 to 751.16 million in 2018, and the penetration rate of the Internet has increased from $47.9 \%$ in 2015 to $54.3 \%$ in 2018. Such a clear upward trend and penetration rate indicate that China has entered the ranks of major Internet countries.

With the development of the global economy, network technology has been unprecedentedly promoted by this economic wave. First, computer information technology has been widely used, which has led to the emergence and development of network technology (Blignaut, Hinostroza, Els \& Brun, 2010). The Internet has such a large audience in China, so it can be seen that human society has entered a new era of knowledge and network. It Leads the economic development of this era to a high-tech-based knowledge economy. The level of education development, the level of scientific and technological research, and the ability of knowledge innovation in a country jointly determine the country's overall national strength and its competitiveness in the international arena. Due to the rapid development of modern technology. The demand for innovative talents has increased substantially, and this new development trend has led the traditional education and teaching model difficult to meet the needs of modern higher education, so it is for educational means. While modernization provides an opportunity, it must require a new leap-forward development in the field of education.

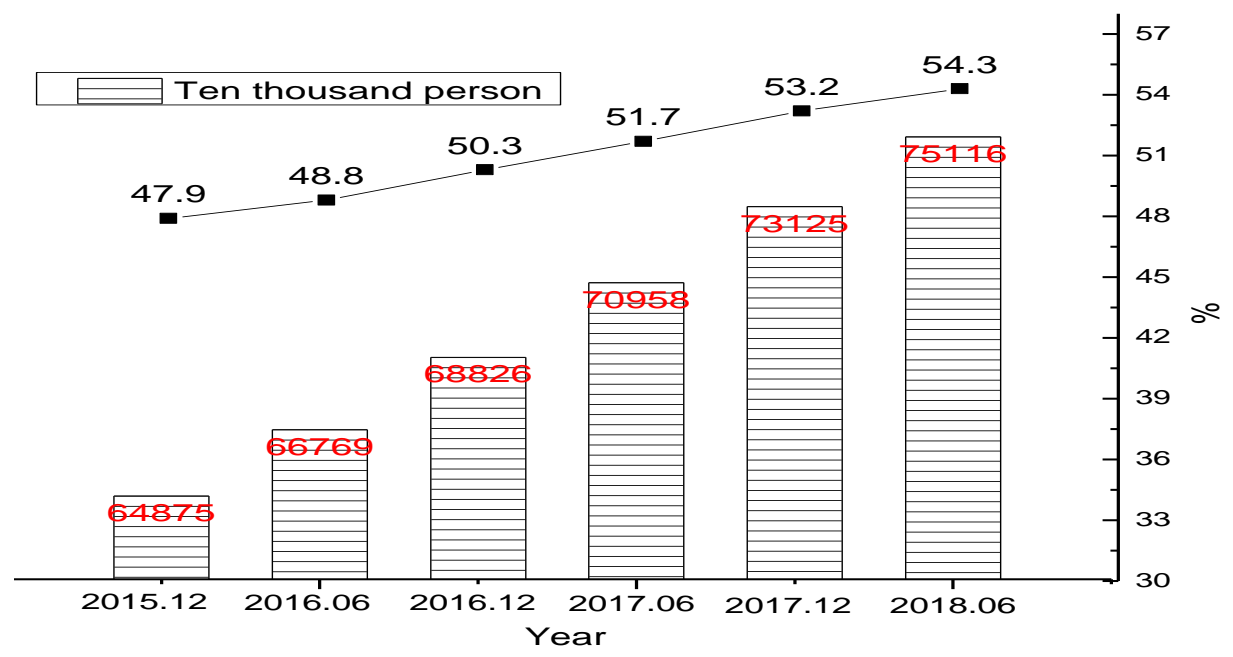

Figure 1. Chinese netizen scale from 2014 to 2018.

\section{Development of distance education}

Under the trend of rapid development of information networking, distance education and online education in various fields have also shown a rapid development trend, and the rapid development of the network has infiltrated and profoundly affected various fields of education. The sports field is bound to be in it, and various 
$\overline{\text { sports information has become an integral part of network resources. This has created an unprecedented network }}$ environment, which provide new opportunities for the development of sports information (Vallance, 2008; Boukouvala et al., 2013). As an important part of college teaching, physical education curriculum has been paid more and more attention. Students are no longer satisfied with the general simple physical activity and physical education curriculum Higher and more scientific theoretical guidance requirements for fitness and extracurricular sports should be put forward. The requirements for sports courses, sports equipment, sports venues and course content in colleges and universities are also increasing. This kind of development trend has made the teachers and classroom resources of college physical education increasingly tense.

The essence of the application of network technology in the distance education of physical education curriculum is that it changes from the teaching mode centered on the teacher's "teaching" to the teaching mode that both teachers and students "learn and teach" (Hartzer, 2014; Yu, 2013). A complete classroom teaching system is composed of four parts: teachers, students, teaching materials and network technology. According to the system theory, these four elements are not isolated and simply combined, but are organic and interconnected interacting, which is as shown in Figure 2. It shows the complex and close relationships in the specific teaching process.

In order to solve this situation, it is necessary to develop sports remote network education. From the current situation of college teaching in China, it is the best way to solve this problem by using modern science and technology to construct a sports distance education website and realize the resource sharing of mass sports. Relying on the campus network, it should give full play to its strong interactivity and freedom from time and space constraints. In the traditional teaching, the teacher's single use of demonstration, visual and voice transfer information to use computer networks and telecommunications networks, and transmit more multiple forms of information. Transforming physical education activities into information in a variety of expressions include video, audio, images, text, and animated content.

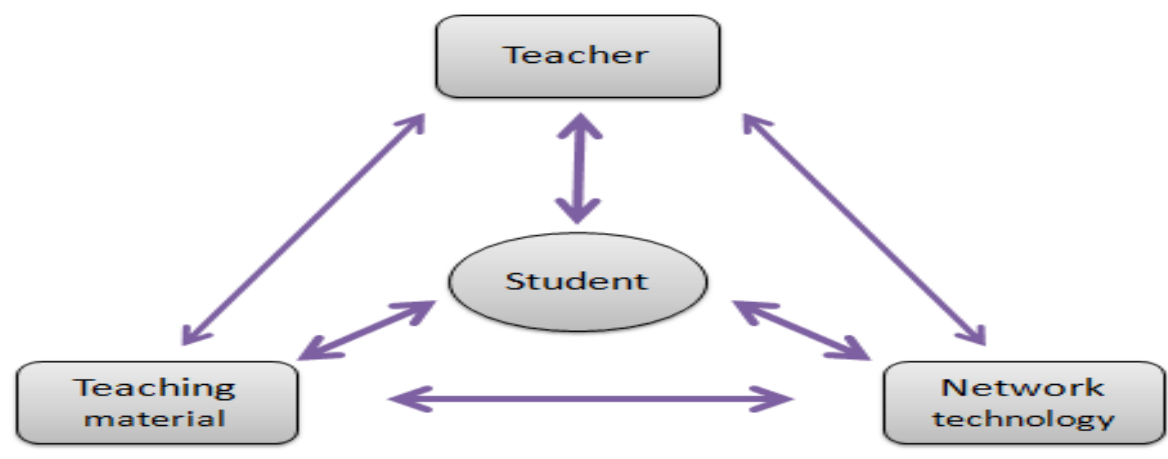

Figure 2. The component of a complete classroom teaching system.

In an effective questionnaire for 136 students (71 boys and 65girls), the results of their sports information show that the average number of students with a sense of network technology is as high as $91.3 \%$, indicating 
that students have already possessed subjective wishes. The awareness of information needs to lay the main foundation for the application of network technology in physical education, which is as shown in Table 1.

Table 1

Students' Perception of Information Needs $(n=136)$

\begin{tabular}{lcccccc}
\hline Index & Important & Percentage & General & Percentage & Unimportant & Percentage \\
\hline Access to information & 136 & 100 & - & - & - & - \\
Information & 110 & 80.88 & 24 & 17.65 & 2 & 1.47 \\
Technology & 123 & 90.44 & 11 & 8.09 & 2 & 1.47 \\
Lifelong sports & 123 & 90.44 & 12 & 8.82 & 1 & 0.74 \\
Assisted instruction & & & & & & \\
\hline
\end{tabular}

Invite 31 modern educational technology experts and school physical education experts (1 researcher, 25 associate professors, 5 professors) to evaluate the feasibility of applying network technology in college physical education. As a result, $97 \%$ of experts believe that network technology application in sports distance learning is feasible, see in figure 3 .

The sports remote network education platform can adopt the network video live broadcast technology, so that students can watch the teaching content at different places at the same time, thus making up for the shortage of teaching resources. In addition, in the school physical education and sports management work, statistics, transcription, calculations, etc., are large in workload and complex in content, plus the uniqueness of sports programs and performance calculations, courses, exams, and physical examinations for students. Work such as quality assessment requires a lot of manpower, material resources and financial resources. Both the physical education teacher and the management of the sports work have increased the workload and the effect is low. Dealing with these physical education and management tasks that contain a large amount of text information, data information, professional technology and theoretical knowledge also require a lot of manpower and financial resources. If you use computer technology, network technology, multimedia technology and modern communication technology, you can avoid a lot of simple and repetitive labor. It can ensure the maximum possible benefit of the school's physical education management work in the implementation process with the least possible investment. Therefore, the realization of information network in school sports management work science, especially the auxiliary management of computer information technology, has important significance for realizing school sports goals. And it is an effective method and means to improve work efficiency and optimize management quality.

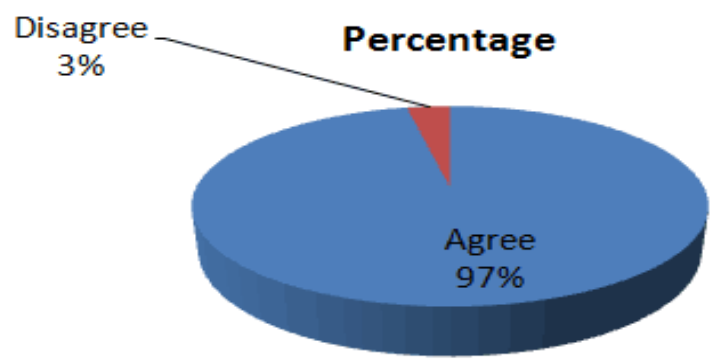

Figure 3. Feasibility assessment of network technology in distance learning of physical education. 


\section{The application network technology in distance education of football education curriculum}

\section{Application advantages of network technology in football education}

The teaching platform and the resources of the sports website are effectively and reasonably integrated to achieve the complementary advantages, break the space and time constraints of traditional physical education, and let some colleges and universities that fail to establish a multimedia network teaching platform for some reason. Students and sports enthusiasts can also learn sports through the multimedia network teaching platform anytime and anywhere, which realizes the optimization of teaching resources. Using the timeliness of the multimedia network and the interaction and display ability, it provides online learning guidance and helps for more college students and non-school sports enthusiasts. In terms of teaching objects, the same faculty conditions, using online education technology to assist teaching, can simultaneously complete sports theoretical knowledge learning and special theoretical learning that is several times higher than traditional teaching students. It can improve teaching efficiency, and the student learning process becomes simpler. You can learn any sports content from any chapter at any time and place. You can also repeat learning, jump learning and use the network to query relevant knowledge outside the school's resource library. It can be clearly seen from Table 2 that football network teaching is more conducive to the mastery of teaching content than traditional football education.

The research shows that the football education curriculum in the network-assisted teaching environment has obvious effects on students' football education ability, lifelong sports awareness and rich sports knowledge. The "New Curriculum Standards" clearly proposes that the ability to acquire sports and health knowledge and methods through the Internet is the horizontal goal of cultivating students' social adaptability. Under the network teaching environment, students pay attention to the use of network resources for independent learning, which is beneficial to the realization of the goal of physical education in this field.

Table 2

Comparison Between Traditional Football Teaching and Online Teaching

\begin{tabular}{ll}
\hline Traditional football teaching & football network teaching \\
\hline Teacher guidance & Student exploration \\
Preaching teaching & Interactive guidance \\
Isolated teaching module for single-disciplinary & Multidisciplinary extension module with \\
disengagement & pragmatic tasks \\
Teacher as a knowledge giver & Teacher as a helper \\
Assessment of factual knowledge and discrete skills & Performance-based assessment \\
\hline
\end{tabular}

The application of network technology will cause great changes in the traditional teaching mode, and indirectly affect the school sports goals through the new teaching mode. It was found that the students' participation and physical condition were significantly different from the control group under the teaching mode, which was significantly better than traditional physical education. The evaluation of students' physical fitness includes the effects of students' physical education and extracurricular exercise. Enhancing the physique of students is the first sports goals for school. Physical education in the network environment does not take enhancing the physique of students as the primary goal of physical education but focuses more on cultivating the consciousness 
and habits of students' exercise, as well as the understanding of sports functions. And it enhances in the form of after-school exercise.

\section{The significance of distance education in physical education curriculum}

With the development of network technology, multimedia technology and network communication technology, more and more students use the network to learn and work. Distance education plays an increasingly important role in the field of school education, and its advantages are increasing. Online teaching is a kind of distance learning. According to the development of major media and information technology, network teaching belongs to the third generation of distance learning. Network teaching is the product of the development of modern network technology and multimedia technology to a certain extent. We made a detailed summary of the three generations of information technology used for teaching and the stage of three-generation distance education (Table 3).

Table 3

Three Generations of Information Technology and Three Generations of Distance Education

\begin{tabular}{llll}
\hline Staging & \multicolumn{1}{c}{ First generation } & \multicolumn{1}{c}{ Second generation } & \multicolumn{1}{c}{ Third Generation } \\
\hline Age & $\begin{array}{l}\text { Mid-19th Century - } \\
\text { Mid 20th Century }\end{array}$ & $\begin{array}{l}\text { Mid-twentieth century - late } \\
\text { eighties }\end{array}$ & $\begin{array}{l}\text { From the 1990s to the } \\
\text { present }\end{array}$ \\
\hline $\begin{array}{l}\text { Distance } \\
\text { education } \\
\text { classification }\end{array}$ & $\begin{array}{l}\text { Correspondence } \\
\text { education }\end{array}$ & $\begin{array}{l}\text { Multimedia teaching } \\
\text { distance education }\end{array}$ & $\begin{array}{l}\text { Open and flexible distance } \\
\text { education }\end{array}$ \\
\hline $\begin{array}{l}\text { Information } \\
\text { technology }\end{array}$ & $\begin{array}{l}\text { Traditional printing } \\
\text { technology } \\
\text { Early audio-visual } \\
\text { technology }\end{array}$ & $\begin{array}{l}\text { One-way transmission-based } \\
\text { electronic communication } \\
\text { technology }\end{array}$ & $\begin{array}{l}\text { Two-way interactive } \\
\text { electronic communication } \\
\text { technology }\end{array}$ \\
\hline
\end{tabular}

It can be seen from Table 3 that since the 1990s, with the generation of network technology and multimedia technology, two-way interactive electronic information communication technology can be realized, which makes the teaching process more open and flexible. Therefore, along with the emergence and development of new technologies, network distance learning has emerged. First, distance education is an important component of the construction of teaching resources. The development of sports distance education platform makes the sharing of physical education resources a reality. It can realize the maximum sharing of information and equipment resources and achieve a breakthrough in teaching content. Second, online physical education, which affects old sports learning concepts, has led to changes in physical education and learning concepts. The sports network education learning platform shows people a new and vast world of sports, providing people with the right and the opportunity to learn sports and sports information. It makes the physical education teaching activities gradually change from the knowledge transfer to the cultivation of students' creative spirit and practical ability, from knowledge learning to knowledge development, which lay the foundation for the maturity of lifelong learning system. Through the timely communication between teachers and students, the quality and efficiency of students' learning is guaranteed. Learners can express their opinions at any time in the online classroom without affecting others' lectures. At the same time, they can also receive education in two or more subjects to achieve the purpose of learning. 


\section{Problems in network distance learning}

Network distance learning needs to establish a certain teaching situation and use the network resource platform to achieve collaborative and autonomous learning. Remote self-learning is a one-to-one interaction between learners and online learning materials, teachers, and classmates. It is not an absolute isolated learning. Self-study is a one-to-one interaction between learners and learning materials. There is no participation of teachers and peers. However, since most teachers have not received the skills training of online teaching, teachers cannot coordinate and organize the courses during the teaching process. Teachers' own quality is limited, it is difficult to strictly follow the teaching rules for the organization and goal setting of online courses. Teachers have some deviations from the educational ideas of online teaching in controlling the teaching objectives and teaching process.

It is a powerful complement to the traditional forms of physical education in schools and provides conditions for individualized learning for learners with special needs. Traditional school sports always revolve around teachers, classrooms, and training, which limit the cultivation and exertion of students' autonomy, making it difficult to implement students in accordance with their aptitude and individualized learning. The establishment of the distance learning platform has opened up a new way for the reform of physical education. The system learning platform provides a huge database, which integrates various information resources such as advanced schools, authoritative institutions and libraries, so that learners can learn and understand current sports dynamics. Development, and the latest knowledge of sports science and technology advancement, at the same time, through the remote network learning platform, can be obtained. Distance education is the actual demand of the school physical education curriculum itself, and it is also the need for the training of physical education talents in the new century. Adapting to the development needs of college education is an important measure to strengthen the soft environment construction of college online courses.

\section{Conclusion}

Network teaching can make up for the shortcomings of traditional teaching content and less class time. the asynchronous teaching nature and modern teaching methods of online education technology are conducive to the exploration of new school teaching mode and the deepening of teaching reform. The application of online education technology has a huge space for development in after-school sports. Using the asynchronous teaching function of online teaching to manage and guide the after-school sports, assist students in independent sports learning, and extend the school physical education classroom, so it has a lot of room for development. In summary, sports distance education not only brings us more opportunities for further study, but also has a farreaching impact on the relevant industries in the country. Sports distance education is a systematic project. It is not only related to the unilateral field of network technology. It is also the future of sports distance education to comprehensively improve its operation mode from the perspective of service. Therefore, for sports distance education, we should not only regard it as a supplementary way of traditional physical education, but also should start a new way out for modern physical education from the long term. 


\section{References}

Beltran-Carrillo, V. J., Devis-Devis, J., Peiro-Velert, C., \& Brown, D. H. K. (2012). When physical activity participation promotes inactivity: Negative experiences of Spanish adolescents in physical education and sport. Youth \& Society, 44(1), 3-27. http://dx.doi.org/10.1177/0044118x10388262

Blignaut, A. S., Hinostroza, J. E., Els, C. J., \& Brun, M. (2010). ICT in education policy and practice in developing countries: South Africa and Chile compared through sites 2006. Computers \& Education, 55(4), 1552-1563. http://dx.doi.org/10.1016/j.compedu.2010.06.021

Boukouvala, F., Chaudhury, M., Sen, R., Zhou, L., Mioduszewski, M., Ierapetritou, G., \& Ramachandran, R. (2013). "Computer-Aided Flowsheet Simulation of a Pharmaceutical Tablet Manufacturing Process Incorporating Wet Granulation." Journal of Pharmaceutical Innovation, 8(1), 11-27. http://dx.doi.org/10.1007/s12247-012-9143-9

Cardinal, B. J., Yan, Z., \& Cardinal, M. K. (2013). Negative experiences in physical education and sport: how much do they affect physical activity participation later in life?. Journal of Physical Education Recreation \& Dance, 84(3), 49-53. http://dx.doi.org/10.1080/07303084.2013.767736

Galán, I., Boix, R., Medrano, M. J., Ramos, P., Rivera, F., \& Moreno, C. (2014). Individual factors and schoolbased policies related to adherence to physical activity recommendations in Spanish adolescents. Prevention Science, 15(4), 588-599. https://dx.doi.org/10.1007/s11121-013-0407-5

Gao, Z., Podlog, L., \& Huang, C. (2013). Associations among children's situational motivation, physical activity participation, and enjoyment in an active dance video game. Journal of Sport \& Health Science, 2(2), 122128. https://dx.doi.org/10.1016/j.jshs.2012.07.001

Hartzer, C. E. (2014). "Commentary: Indiana education reform and fiscal stress: Practitioners' curiosity." Public Administration Review, 74(5), 614-615. https://dx.doi.org/10.1111/puar.12255

Rajkumar, V., \& Bhudev, S. (2016). Prioritized information fusion method for triangular fuzzy information and its application to multiple attribute decision making. International Journal of Uncertainty, Fuzziness and Knowledge-Based Systems, 24(02), 265-289. http://dx.doi.org/10.1142/S0218488516500136

Vallance, M. (2008). Beyond policy: strategic actions to support ICT integration in Japanese schools. Australasian Journal of Educational Technology, 24(3), 275-293. http://dx.doi.org/10.1007/s12247-0129143-9

Yu, D. (2013). Prioritized information fusion method for triangular intuitionistic fuzzy set and its application to teaching quality evaluation. International Journal of Intelligent Systems, 28(5), 411-435. http://dx.doi.org/10.1002/int.21583 